\title{
Task complementarity in academic work: a study of the relationship between research, education and third mission tasks among university professors
}

\author{
Ingvild Reymert ${ }^{1,2} \cdot$ Taran Thune $^{1,3}$
}

Accepted: 28 December 2021 / Published online: 18 January 2022

(c) The Author(s) 2022

\begin{abstract}
Professors have multiple responsibilities and tasks. They should contribute to research, teaching and 'third mission' activities such as commercialisation of scientific knowledge and industry collaboration. These tasks are expected to be complementary and that synergies between different tasks can lead to positive outcomes. But are professors' work tasks really complementary or are they rather characterised by trade-offs, and what are the implications of having multiple tasks for academic performance? This study of tenured academic staff in Norwegian universities, observe that there are many positive associations between academic tasks. The data supports the assumption that student supervision is positive for research performance, as is research collaboration with public and private organisations. We also find a positive association between student supervision and participation in third mission activities, but only with research collaboration and not commercialisation activities. The data also indicates that the combined effect of participation in third mission and teaching activities is neither negative nor positive for research performance, and as such we do not find indications that having multiple task is negative for work performance in the form of research output.
\end{abstract}

Keywords Academic work · Task complementarity $\cdot$ Research performance $\cdot$ Educational responsibilities $\cdot$ Commercialisation $\cdot$ Research collaboration

JEL classification $\mathrm{I} 23 \cdot \mathrm{O} 31 \cdot \mathrm{O} 34$

Taran Thune

taranmt@tik.uio.no

Ingvild Reymert

Ingvild.reymert@nifu.no

1 Nordic Institute for Studies of Research, Education and Innovation (NIFU), Oslo, Norway

2 Department of Political Science, University of Oslo, Oslo, Norway

3 Center for Technology, Innovation and Culture, University of Oslo, Oslo, Norway 


\section{Introduction}

Universities have multiple missions and are expected to contribute to generating new knowledge through research and educating new generations of scholars and professionals. Universities are also expected to contribute to the so-called 'third mission'which concerns the diffusion and use of knowledge in society and the economy broadly defined (Laredo, 2007, Sanchez-Barrioluengo, 2014; Stolze \& Sailer, 2021). Reflecting these trends, debates on academic careers, and how to balance teaching, research and third mission activities, are ongoing discussions in many countries and higher education institutions (Sanchez-Barrioluengo, 2014). More recently, initiatives have emerged in several universities and higher education systems to support career development practices that encompass multiple competences and a broad set of qualifications and career assessment criteria. As Van den Brink and Benschop (2011) succinctly put it, professors are increasingly asked to be "sheep with five legs" and must become efficient multitaskers to cope with an increasing number of tasks and responsibilities in their work.

Higher education policies and management practices are based on the premise that different academic tasks and activities at least to some degree are complementary. This idea is explicated in concepts like 'research-based education' and 'academic entrepreneurship'. But compared to the optimism inherent in policy and practice, empirical research has emphasised trade-offs between tasks (Fox, 1992; Kossi et al., 2016; Artes et al., 2017). Several studies have identified limited complementarity between research and third mission activities (e.g. Gulbrandsen \& Smeby, 2005; Van Looy et al., 2004), and research on the relationship between teaching and research do in general not demonstrate a high degree of complementarity either (Hattie \& March, 1996; Verburg et al., 2007; Landry et al., 2010; Kossi et al., 2016). Moreover, there is limited research into the complementarities between teaching and third mission tasks (Wang, et al., 2016; Bianchini et al., 2016; Fudickar et al, 2018) and few studies attempt to look at academic work across all task domains (Landry, 2010; Bianchini et al., 2016). It is still necessary to build systematic knowledge on academic task complementarity, and with this in mind, this paper address the following research questions: From the perspective of academic staff, to what extent is it possible to achieve complementarity between tasks, and what does having multiple tasks mean for academic work performance? Further knowledge on this issue is relevant for policy makers, university managers and academics trying to grapple with how to balance multiple work tasks and its impact on academic workload and performance.

To shed light on the questions, we analyse a dataset that contains information on the academic work of 1475 Norwegian university professors (tenured faculty; associate and full professors) across all fields of science. The Norwegian university setting is a suitable context to study the question of task complementarity as Norwegian university professors are expected by their employment contracts to contribute to research, education and third mission activities (Bentley \& Kyvik, 2012; Frølich et al., 2018). This leaves us with a large sample of professors with similar task requirements where we can investigate how professors behave in multiple task domains.

Before presenting the methodological approach, we review existing research on task complementarity in academe and outline a set of expectations to guide our analysis. We then describe the main results obtained and discuss the results in light of existing literature. The concluding section discusses the limitations of the study and the implications for further research, management and policy. 


\section{Literature on task complementarity in academic work}

The question of task complementarity at work is a broad research topic and has been addressed in fields such as psychology and sociology of work, management studies as well as in labour economics. In terms of the latter, task specialisation has traditionally seen as efficient, and associated with a 'Tayloristic' organisation model where specialisation of tasks is seen as the basis for efficiency and productivity in work. According to Lindbeck and Snower (2000), reorganisation of work towards multitasking has become increasingly common, spurred on by development of advanced production technologies, digital tools and increased education in the population. One argument for multitasking is that it increases learning and thereby performance. As a result of increased prevalence of multitasking, research has also documented a range of negative effects for the individual (dissatisfaction, burn-out etc.), as well as a negative impact on work performance and overall productivity. Doing several tasks at once is not however the same as performing multiple tasks, and the question of task complementarity does not necessarily entail multitaskingas tasks can be carried out both in parallel and sequentially.

The basic assumption underlying critical perspectives on multitasking is that there is a constraint in having too many work tasks, as attention, time and resources are limited. Further, that negative effects of multitasking are exacerbated when tasks are not complementary. Complementarity exists when there is a spill-over effect and where resources (including knowledge and time) involved in performing one task also can be used in the execution of another. The magnitude of the task in question of course also plays a role, as time is a limited resource for everyone. Task complementarity is hence dependent on both the kind of tasks and the magnitude of the tasks to be performed. Pertinent questions then become whether the work tasks of academics are complementary or not, and whether having a broad portfolio of work tasks is positive or negative for work performance.

As seen above, university professors have long been expected to perform multiple tasks. As professors have a high degree of autonomy in their work and a high level of competences in their work domains, achieving task complementarity might be more feasible for them than for other categories of employees (Pelz \& Andrews, 1966). To look at this in more detail, we review existing literature from the higher education and science studies fields to identify how the issue of task complementarity has been addressed in an academic setting. As research has predominantly looked at task complementarity in pairs of activities, such as the relationship between teaching and research, prior research on each pair of tasks is reviewed below. Based on the review, a set of propositions to guide our empirical study is outlined.

\subsection{Relationship between teaching and research tasks}

In most higher education systems, there is a shared view that there should be a relationship between educational responsibilities and research activities. The basic idea, stemming from the notions of Humbolt about the unity of research, teaching and learning (Nybom, 2003), is that research and educational activities should be complementary. The knowledge generated by academics through research activities should spill over to teaching and supervision of students, in the form of deeper knowledge, broader understanding of the literature, 
advanced analytical and methodological skills etc. Derived from this perspective, a basic assumption would be that academics who are active researchers are also good teachers and educators, due to their more substantial knowledge of the scientific field. The relationship is usually investigated in this direction (i.e. influence of research on teaching), and seldom on the other way around, even though it is assumed that teaching, and particularly supervision of graduate students, have positive effects on research (e.g. Duff \& Marriott, 2017).

As the potential synergy between teaching and research in higher education institution is a fundamental question within the field of higher education research, a large number of studies have been performed on this issue. Studies have often formulated the relationship between research and educational tasks as a trade-off (Fox, 1992; Landry et al., 2010; Artes et al., 2017). According to their argument, investing time and resources in research activities means forgoing time that could be invested in education activities, or vice versa. Hattie \& March (1996) and Braxton (1996) published early meta-analyses of the evidence about the link between teaching and research and reach similar conclusions. Their metaanalyses indicated that there was no significant relationship between research and teaching performance, neither positive nor negative. A more recent literature review on the same issue discusses this conclusion and finds that it is difficult to systematically assess this question, as the concepts teaching, and research performance are not operationalised in similar fashion and that the variables used in most studies are limited (Verburg et al., 2007). In particular, the operationalisation of teaching varies a lot. Verburg et al. (2007) show the variety of different aspects and measures of teaching used, including: Teaching quality, the time used on teaching, the number of courses taught, the amount of interaction with students, the researchers' pedagogical approaches, the researchers' attitudes to teaching, teaching skills, commitment to teaching, investments in teaching, and supervision of students. Student evaluation scores or ranking scores of the institutions have also been used as indicators of academic's teaching activities (e.g. Bianchini et al., 2016), but they are also criticised (e.g. Wiers-Jenssen, 2015).

Moreover, studies have tended to look at the relationship as a linear one, but later studies have indicated that there might be a threshold effect involved (Artes et al., 2017; Bianchini et al., 2016). The latter indicates that research activities up to a certain level is positive for teaching, but when a threshold is met, the positive effects diminish (Garcia-Gallego et al., 2015). It is also important to highlight that most studies reviewed look at the effect of research on teaching. This again could have impact on the expected relationship between the two variables. Research activities might be positive for teaching, but we have limited understanding of whether teaching is positive for research (Landry et al., 2010).

Based on the available insights into relations between these tasks, we expect that there is some degree of complementary between educational responsibilities and research activities, at least up to a certain level of educational responsibilities. Moreover, as educational responsibilities are manifold and varied, they need to be studied as a set of different activities. Supervising students reflect one important part of professors' work obligations and is also the teaching activity that may be most integrated with research. Due to this, we choose to study supervision activities as an indicator of educational responsibilities. With this in mind, we expect a positive relationship between moderate levels of educational responsibilities, here in the form of supervision of students, and research (proposition 1). 


\subsection{Relationship between third mission activities and research tasks}

Considerable research has also been performed on the relationship between research and third mission tasks. Following Sanchez-Barrioluengo (2014) the concept 'third mission' activities is here used for a range of different activities performed by academics to utilise their knowledge and expertise outside the academic context. As has been described by others (Molas-Gallart, 2002; Perkmann et al., 2013; Sanchez-Barrioluengo, 2014) this concept is made up of heterogeneous sets of activities, where some are more prevalent across all fields of science and some are exclusive to specific fields. Early research on this issue focused on mostly on activities directed to commercialisation of academic knowledge, such as patenting, licencing, and industry partnerships (Geuna \& Nesta, 2006; Gulbrandsen \& Smeby, 2005; Lee \& Bozeman, 2005), but these are mainly found in sciences, technology and engineering as well as in biomedicine. Later research that widened the empirical focus outside engineering and sciences, and found that academics in most fields of science utilised their knowledge in external communities, through collaborating and communicating with stakeholders and the public in many different ways (e.g. Abreu \& Grinevich, 2013; Perkmann et al., 2013; Perkmann et al., 2021).

Following Perkmann et al. (2013), we distinguish between two modes of utilising scientific knowledge and expertise outside academia—research commercialisation and research collaboration. This distinction is also made by Bozeman et al. (2013) who discern 'property focused' and 'knowledge focused' forms of collaboration. Both kinds of activities entail that academics actively pursue activities to diffuse and make use of scientific knowledge in external communities and contexts. The first in the form of ensuring ownership and transferring the rights to exploit scientific knowledge commercially in the form of patents, licenses or other activities based on proprietary knowledge. The latter research collaboration-entails diffusing knowledge to firms and public sector organisations, in the form of research agreements, partnerships, consulting and advisory activities, etc. In resent research, such activities are often labelled "academic engagement" (Perkmann et al., 2013, 2021) or "academic knowledge exchange" (Hayter et al., 2020) to capture the broader set of activities that academics in different fields of science are involved in.

The relationship between these activities and research is likely different for different kinds of third mission activities (Perkmann et al., 2013). Prior literature that has looked at the impact of participation in commercialisation on research performance, usually measured by publication data, indicates a positive relationship (Buenstorf, 2009; Geuna \& Nesta, 2006; Larsen, 2011). There seems to be some degree of complementarity between these tasks, where academics that are active in commercialisation activities also score highly on research productivity. This effect seems to be more prominent in some disciplines, and particularly in the life sciences (Roche et al, 2020), and it also seems to be mediated by the status and age of academic employees, as well as their research orientation (Rothaermel et al., 2007; Perkmann et al., 2013; Abreu \& Grinevich, 2013; Bianchini et al., 2016, Fini et al., 2021). It seems that engagement in commercialisation can be associated with high research performance, but the temporal dimension is important as high research performance in most cases precede commercialisation. One might however assume that for academic entrepreneurs that continue to stay in academe, resources from commercialisation activities are channelled back to support new research initiatives, and therefore can enhance future research performance (Breschi et al., 2007; Buenstorf et al., 2009). 
Research has also looked at the relationship between external collaboration and research performance. Early contributions to this literature found a positive relationship between industry partnerships and research performance, but mainly in technology and natural sciences (Abramo et al., 2009; Gulbrandsen \& Smeby, 2005; Van Looy et al., 2004). Recent analyses have attempted to look deeper into this issue, by measuring different levels and kinds of collaboration, and their association with research performance. The empirical evidence indicates that the association between the variables is not linear (Muscio et al., 2017; Banal-Estanol et al., 2015), but that up to a certain level, being involved in external collaboration is positive for research performance.

Based on the reviewed literature, we make two expectations about the complementarities between third mission tasks (distinguished by the two different modes, as described above) and research: We expect that there is a positive association between commercialisation and research tasks (proposition 2). As it is a limited number of academics that are involved in commercialisation activities, we do not expect to be able to distinguish between levels of participation on this variable. We also expect a positive relationship between moderate level of external collaboration and research performance (proposition 3). For the latter expectation, prior research indicates that a threshold may be involved, so we have included this in our analysis.

\subsection{Relationship between educational responsibilities and third mission tasks}

This relationship is less well documented (Perkmann et al., 2013; Bianchini et al., 2016) partly because there is a lack of available studies and adequate data, but also because there is limited understanding of how educational activities are connected to research work, as discussed above. Some authors claim that resources, knowledge and networks available through academic entrepreneurship and external collaboration can influence education and instruction positively (Etzkowitz, 1998). For instance, Lin and Bozeman (2006) found that academics who collaborate with industry, support and supervise more graduate students compared to peers who do not collaborate with industry. Bozeman and Boardman (2013) have also found a positive relationship between industry collaboration and support to students at both undergraduate and graduate levels. Other authors claim that the relationship is negative, and that third mission tasks might reduce the time and effort academics spend on teaching and other educational tasks (Gulbrandsen \& Smeby, 2005).

Wang et al. (2016) operationalised third mission tasks in two separate models, following Perkmann et al. (2013), and proposed that the two models have different kinds of impact on teaching activities. Wang et al. (2016) assumed that commercialisation is not positive for teaching performance, but that research collaboration would be. They find support for their hypotheses and also that the combined model (high on commercialisation and high on research collaboration) is positive for teaching performance. Contrary to this finding, Bianchini et al. (2016) found that faculty who perform extraacademic tasks (measured by consulting activities) have 'lower commitment to teaching'. Similar results were also obtained in studies made by Lee and Rhoads (2004) and Sanchez-Barriolungo (2014). Bianchini et al. (2016) highlight that there are substantial disciplinary differences. Landry et al. (2010), on the other hand, find no significant 


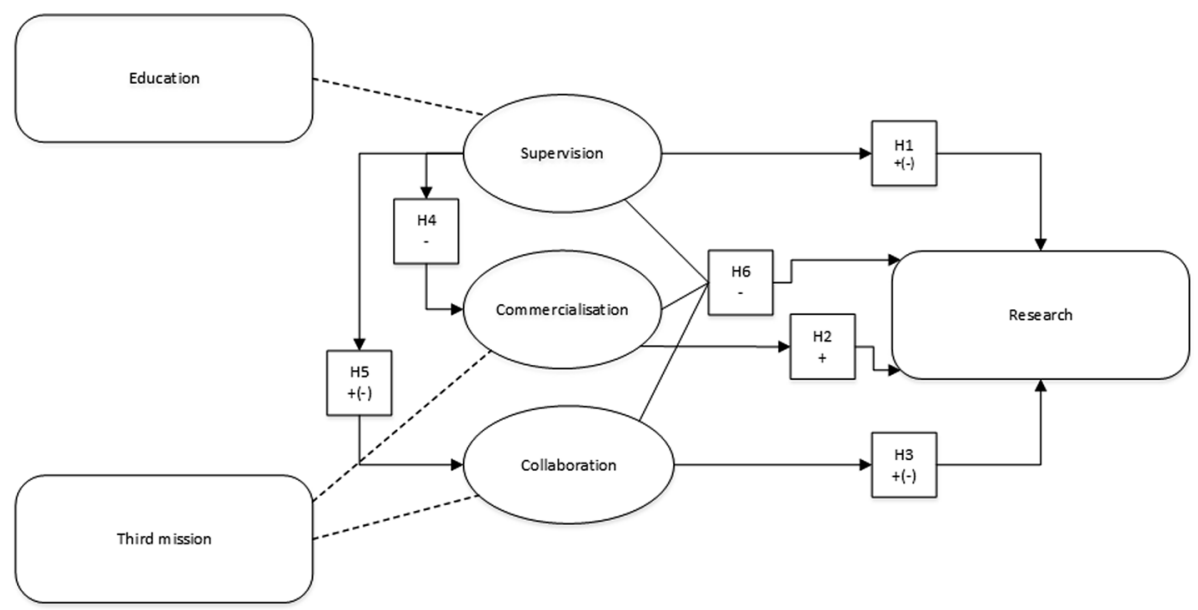

Fig. 1 Main concepts and expected association between them. $\mathrm{P}=$ proposition; + indicates a positive association; - indicates a negative association and + (-) indicates a positive association with a threshold effect

relationship between teaching and commercialisation and other knowledge transfer activities.

Based on these insights, we formulate two expectations to guide research, and we discern third mission tasks directed at commercialisation and collaboration (e.g. Perkmann et al., 2013). We expect that there is a negative relationship between educational tasks and commercialisation (proposition 4). Finally, based on Wang et al. (2016) and the general pattern of threshold effects found in related research, we expect a positive relationship between moderate levels of educational tasks and external collaboration (proposition 5).

\subsection{Task complementarity and work performance}

In the literature on academic work reviewed above, there is an expectance that there is a positive association between tasks, dependent on controlling the volume of each task. Figure 1 illustrates the main concepts and summarises the expected associations between them.

Educational tasks (here measured by supervision) is expected to be positively related to research performance, when the level of supervision duties is not too high (complementarity is moderated by volume) (P1). Similar, engaging in third mission activities (measured by external collaboration and commercialisation of research) is also assumed to have spill over effects that influence research in a positive way (P2 and P3) when moderated by volume (for collaboration). These expectations assumes that there is a possibility of using resources from one task (e.g., involving students in research work or collaborating with an external partner) in such a way that it influences research activity and output.

Whether teaching responsibilities and third mission activities (collaboration and commercialisation) (P4 and P5) are associated in a positive way was however unclear 
in the literature. We assumed that there is a positive relationship between supervision and external collaboration, but not between supervision and commercialisation. The final expectation is that the combined efforts of being involved in both third mission activities and teaching related tasks will be negatively related to research performance, due to increased overall workload (Proposition 6). Finally, as the model assumes that the variables are interdependent, we introduce interaction terms in the analysis.

To explore the propositions we perform regression analyses, but we do not aim to test a causal model or predict academics' behaviour. The propositions address the correlation between tasks and the results of the study should not be interpreted in causal terms.

\section{Data, measurements and methods}

\subsection{Sample and sources of data}

To investigate task complementarity in academic work, we used data from a survey of academic staff in Norway. To draw the sample, we utilised a database of all scientific staff employed in Norwegian research organisations (the national registry of research person$n \mathrm{l}^{1}$ ). The database includes names, gender, age, institutional affiliation, position and home address to all research staff in the public sector research organisations, and it is updated on an annual basis. The sample for the survey was drawn from the registry and the survey was administered to all individuals who were permanent employees (excluding $\mathrm{PhD}$ students, post docs and short-term, temporary staff) in the university sector. The survey was administered in $2014 .^{2} 8585$ individuals received an invitation to respond, and it received a 52.5\% response rate. The survey collected demographic information about the academic employees and their participation in different research, education and third mission activities. We also matched the respondent in the survey with their publication records drawn from a database that contains the bibliometric records of all scientific employees in Norway. ${ }^{3}$ This data source was used to construct the research variables.

For this specific analysis, we needed to select a sample from the population that had relatively similar working conditions and expectations to contribute to all three tasks. As the Norwegian higher education system is a binary system with two main types of institutions research-intensive universities and teaching-intensive university colleges or polytechnics, the institutional missions and the working conditions of the academic staff, particularly when it comes to time available for research, are different. Moreover, academic positions and ranks entail different work conditions and time available to do research. Prior analysis of the data set showed that academic staff in the rank of professor (associate and full professors; all tenured) have relatively similar working conditions and receive approximately the same amount of time for research activities. To control for the institutional and positional differences that influence the respondents' academic work, and to ensure a relatively high level of research activity among the respondents, only tenured faculty employed at the four comprehensive universities were selected. Our final analysis included 1475 responses,

\footnotetext{
1 https://www.nifu.no/fou-statistiske/forskerpersonalregisteret/.

2 The survey is carried out at regular intervals; about every ten years. The data used here is from the latest wave (2014).

3 https://www.cristin.no/english/.
} 
which represent $42 \%$ of the whole population of professors (full and associate professors) in Norway at the time of the survey.

\subsection{Operationalisation of variables}

\subsubsection{Research tasks}

In studies of academic work and performance, bibliometric data are often used to measure individuals' research activities and performance. We use the same approach to measure the volume of research tasks a given academic performs. The number of scientific publications produced by the academics in the years 2011-2013 (the three years prior to the administration of the survey) was collected from a Norwegian bibliographic database and matched with the respondents in the survey. The bibliographic database contains all publications produced by Norwegian academics with a complete coverage of all peer-reviewed scientific and scholarly publications, including journal articles, monographs, book chapters and conference proceedings in all fields of research, and to capture the broad coverage of outlets, publications are awarded "publication points" depending on the type of outlet and individual contributions of the authors (Sivertsen, 2016). In the analysis, we use publication data from each individual over the three years prior to the survey, and calculate two variables. First, we use a dummy variable in the regression analysis $(0=$ having no registered publication points in the three years prior to the survey; $1=$ at least one publication point). A second variable measures research productivity by the log of the number of publication points, as the number of publication points is very skew.

\subsubsection{Education tasks}

Prior studies have used many different operationalisations of education and teaching tasks, including teaching hours, number of programs taught, number of students supervised, and subjective assessments of time spent on teaching-related activities. The exact amount of time spent different education and teaching activities would be the ideal way to measure it, but time estimates are known to be complicated (Eurostat, 2019) and it is difficult, if at all possible, to obtain access to administrative data (time sheets). The number of students supervised has previously been used as an indicator of teaching activity in several studies (Lin \& Bozeman, 2006; Bozeman \& Boardman, 2013; Kyvik \& Smeby, 1994), but is better at capturing graduate rather than undergraduate teaching. Moreover, as supervision represents a teaching practice where professors use their research skills actively, it represents a good example of a setting where task complementarity is expected. Hence, we have chosen this measure in this analysis, after trying out several measures that were meant to capture the amount of time academics spent interacting with students. When choosing to operationalise academics' educational tasks in terms of supervision of students, we are aware of the fact that our variable does not cover most teaching activities but argue that supervision is both an important part of academic teaching and also a relatively reliable indicator.

In the survey, the respondents were asked to report the number of bachelor and master students they supervised at the time of the survey. This means that this is a quantitative indicator, but since we are interested in complementarities and trade-offs between tasks, the amount of an activity is relevant for us, as it reflects the time and resources invested in performing this task. $99 \%$ of the respondent reported that they supervised between zero 
Table 1 The variables used in the analysis

\begin{tabular}{|c|c|c|c|}
\hline Variable & Values & Frequency & Percent \\
\hline \multirow[t]{2}{*}{ Gender } & Female $=0$ & 443 & 30 \\
\hline & Male $=1$ & 1032 & 70 \\
\hline \multirow[t]{4}{*}{ Age } & Less than 40 years & 130 & 9 \\
\hline & $40-49$ years & 368 & 25 \\
\hline & $50-59$ years & 498 & 34 \\
\hline & 60 years or more & 479 & 32 \\
\hline \multirow[t]{5}{*}{ Academic field } & Humanities & 338 & 23 \\
\hline & Social sciences & 387 & 26 \\
\hline & Natural sciences & 247 & 17 \\
\hline & Technology & 219 & 15 \\
\hline & $\begin{array}{l}\text { Medicine and health (reference } \\
\text { category) }\end{array}$ & 284 & 19 \\
\hline \multicolumn{4}{|l|}{ Research activity } \\
\hline Publication points & \multicolumn{3}{|c|}{$\begin{array}{l}\text { Min. value }=0, \text { max value }=23,4, \text { mean } 3,337, S D=3,103 \\
10 \text { percent }(152) \text { has zero publication points }\end{array}$} \\
\hline \multirow[t]{2}{*}{ Having publication points (dummy) } & Have $=1$ & 1323 & 90 \\
\hline & Have not $=0$ & 152 & 10 \\
\hline \multicolumn{4}{|l|}{ Teaching activity } \\
\hline Supervision & \multicolumn{3}{|c|}{ Min. value $=0$, max value $=42$, mean $4,587, S D=5,836$} \\
\hline \multirow{5}{*}{$\begin{array}{l}\text { Number of student supervising } \\
\text { (Categorical variable) }\end{array}$} & Zero students & 330 & 22 \\
\hline & $1-5$ students & 727 & 50 \\
\hline & $6-10$ students & 252 & 17 \\
\hline & $11-20$ students & 111 & 8 \\
\hline & 20 students & 39 & 3 \\
\hline \multicolumn{4}{|l|}{ Participation in third mission activity } \\
\hline \multicolumn{4}{|l|}{ Commercialization } \\
\hline Developed new products & & 165 & 11 \\
\hline Applied for patent & & 95 & 7 \\
\hline Started new firm & & 48 & 3 \\
\hline Licensed & & 27 & 2 \\
\hline \multicolumn{4}{|l|}{ Research collaboration } \\
\hline Contract research & & 216 & 15 \\
\hline $\begin{array}{l}\text { Collaboration R\&D with public } \\
\text { sector }\end{array}$ & & 271 & 19 \\
\hline $\begin{array}{l}\text { Collaboration R\&D with private } \\
\text { sector }\end{array}$ & & 290 & 20 \\
\hline
\end{tabular}

and 42 students, while one percent answered between 43 and 172 students. We defined this latter percent of respondents as outliers and removed them from the final sample. But as the number of students supervised is highly skew, we calculated two variables: a dummy variable and a five step categorical variable with the number of students one supervise. 


\subsubsection{Third mission tasks}

As discussed above, third mission activities involve many and rather different activities, but it is customary to discern activities directed at commercialisation and collaboration (e.g. Bozeman et al., 2013; Perkmann et al., 2013). We operationalise third mission tasks in correspondence with this distinction. The respondents were asked to report their research collaboration activities (including contract research and research collaborations with industry and public sector organisations) and their participation in research commercialisation activities (contribution to the development of new products, applied for patent, started new firm, licensed out proprietary knowledge). The latter activities are mainly carried out by researchers in the STEM-fields, whereas research collaboration (with private and public partners) is much more distributed and common in most fields of science.

Finally, in the analyses we control for gender, age, academic field and institution, as these variables impact on academic work and time available for different activities, and therefore need to be considered (Table 1).

\subsection{Regression analyses ${ }^{4}$}

While the education and third mission variables are self-reported activities, the research variable measure the output of research activities and hence it is treated as the dependent variable. In the analysis, we first investigated the relationship between the two independent variables (proposition 4 and 5) and analyse differences in the amount of third mission activities performed by academics who supervise students and those who do not. Third mission activities were set as the dependent variables, and to control for potential effects of gender, age and academic field, logistic regression models were used. ${ }^{5}$ Significant differences were tested by using a two-dimensional test for random selection at five percent.

In the second step, we investigated how participating in supervision and third mission activities relate to research (propositions 1, 2 and 3) using logistic regressions with research as the dependent variable. We first treated research output as a dummy variable (having or not having published during a three-year window), and also conducted the analyses with the log of the number of publications that is a better indicator of research productivity. In the latter analysis we used an OLS-model. We also investigated the interaction between supervision and third mission activities, and how the interaction between the independent variables influenced research output (proposition 6). In the analyses, we also applied the variance inflation factors-test (VIF-test) to control for eventual multicollinearity (Lin, 2008).

In a third step, and mainly to control the results, we run a separate model with only parts of the sample. Since it is more common for researchers within the STEM-field to participate in third mission activities, and particularly commercialisation, we also ran a separate the analysis on this group. However, this analysis did not produce significantly different results from the analyses of the whole sample, and instead confirmed our overall conclusions.

\footnotetext{
${ }^{4}$ The analysis was conducted by the data program $\mathrm{R}$, and the script can be provided upon request.

${ }^{5}$ Regression tables are found in Appendix Tables 4, 5 .
} 


\section{Results}

In line with the expectations, the first analysis (see Appendix Tables 4, 5, 6, 7) indicates a positive relationship between supervising students and participating in research collaboration. Professors who supervised students were more actively engaged in research collaboration compared to their peers who do not supervise students, and this difference is significant (see Table 2). This positive association was particularly strong for ' $R \& D$ collaboration with public sector' and 'contract research'. The logistic regression analysis also confirmed a positive relationship between the number of students supervised and research collaboration (proposition 5). However, the relation between supervision and commercialisation was not significant. Thus, proposition 4 that estimated a negative relationship between educational tasks (here limited to supervision) and commercialisation, was rejected due to lack of supporting evidence.

The main analysis included supervision and third mission activities as independent variables, and research output as the dependent variable (Table 3). In line with proposition 1, the analysis showed a positive relationship between supervision and research activity. Even though the number of students did not affect the research output, the analysis with the categorical threshold variable (Appendix Table 9) showed that supervising 1-5 students had strongest positive effect on research output, while supervising more than 20 students had no significant effect. As expected, a threshold effect was at play between supervision and research tasks and only moderate volumes of supervision work were positive for research output.

As described, we operationalised third mission activities in two separate categories commercialisation and collaboration. Both were expected to be positively associated with research activities, but the findings indicate that only research collaboration is positively related to research output. None of the commercialisation variables had significant effects on research output. ${ }^{6}$ Moreover, the effect of the collaboration variable is reduced when controlled for supervision activities (model 6 and 7 in Table 3), implying that the effect of participating in collaboration on research output is of moderate character.

We also conducted an OLS-regression analysis with the log of the number of publication points as dependent variable. Here we do not find a significant effect of teaching activities or third mission on the volume of research output (Appendix Table 8). This implies that the effect we find of teaching and third mission activities are relatively moderate. We find that participating in these activities explain whether academics publish or not, but they do not explain scientific productivity, when also controlling for a range of other factors.

Finally, we looked the interaction of supervising and third mission activities and its impact on research output (Appendix Table 11). The interaction effect was negative, but not significant. This implies that while both activities were positive for research output separately, but this positive effect cannot be seen for the combination of both tasks. But doing both did not reduce research output either. Thus, proposition 6 , where we assumed that the combination of third mission and supervision activities would be negatively associated with research performance, cannot be supported.

Results from logistic regression analysis can be difficult to interpret. To illustrate the implication of the results obtained, we have calculated the probabilities of having no

\footnotetext{
6 The regression analysis with the commercialisation variables are excluded from Table 3 to avoid data overload but can be seen in Appendix Table 10.
} 
Table 2 Researcher's participation in commercialization and research collaboration after whether they supervise students or not. Percentage

\begin{tabular}{lcc}
\hline & Supervised (\%) & $\begin{array}{l}\text { Not super- } \\
\text { vised (\%) }\end{array}$ \\
\hline Commercialization & & \\
Developed new products & 11.2 & 11.5 \\
Applied for patent & 6.7 & 5.8 \\
Started new firm & 3.8 & 1.5 \\
Licensed & 1.8 & 2.1 \\
Research collaboration & & \\
Contract research & 16.7 & 8.2 \\
Collaboration R\&D with public sector & 19.9 & 13.6 \\
Collaboration R\&D with private sector & 21.7 & 13.9 \\
\hline
\end{tabular}

publication points (no research activity in our operationalisation) for male professors in technology (probabilities calculated from model 6 in Table 1). Figure 2 shows that $11 \%$ of professors that supervise students have no publication points, compared to 22 percent of those that do not supervise. Similarly, while only 6-7\% of male technology professors that are involved in different forms of research collaboration have no publication points, 11 percent of male technology professors that do not participate in such activities have no registered publication points in a three year period.

\section{Discussion}

The analyses provide us with mixed evidence on the potential complementarities and tradeoffs between academic tasks. Based on prior research we expected that there would be a positive or synergistic relationship between participating in educational tasks and research activity. Recent research indicates complementarity between teaching and research up to a certain level whereby the positive effect of teaching activities on research decrease (Bianchini et al., 2016, Garcia-Gallego et al., 2015; Artes et al., 2017). In our analysis, we find support for this assumption, as the analyses find that supervising students is positively associated with research activity, at least up to a certain level or volume of supervisory activity. In line with prior research, we also find that this form of task complementarity is particular for graduate level teaching and supervision (Lin \& Bozeman, 2006), as this educational activity is expected to draw on research experience to a larger extent. We also find that supervision is not associated in a positive way with research productivity (measured by the $\log$ of publication points). This entails that research activity is related to supervising students, as students assumingly contribute with some labour as well, whereas a high level of research performance might be favoured by a concentration on research tasks only.

We also investigated relationships between third mission and research activities. We expected a positive relationship between commercialisation and research activity (Perkmann et al., 2013), but did not find clear support for this. In line with our expectation and 


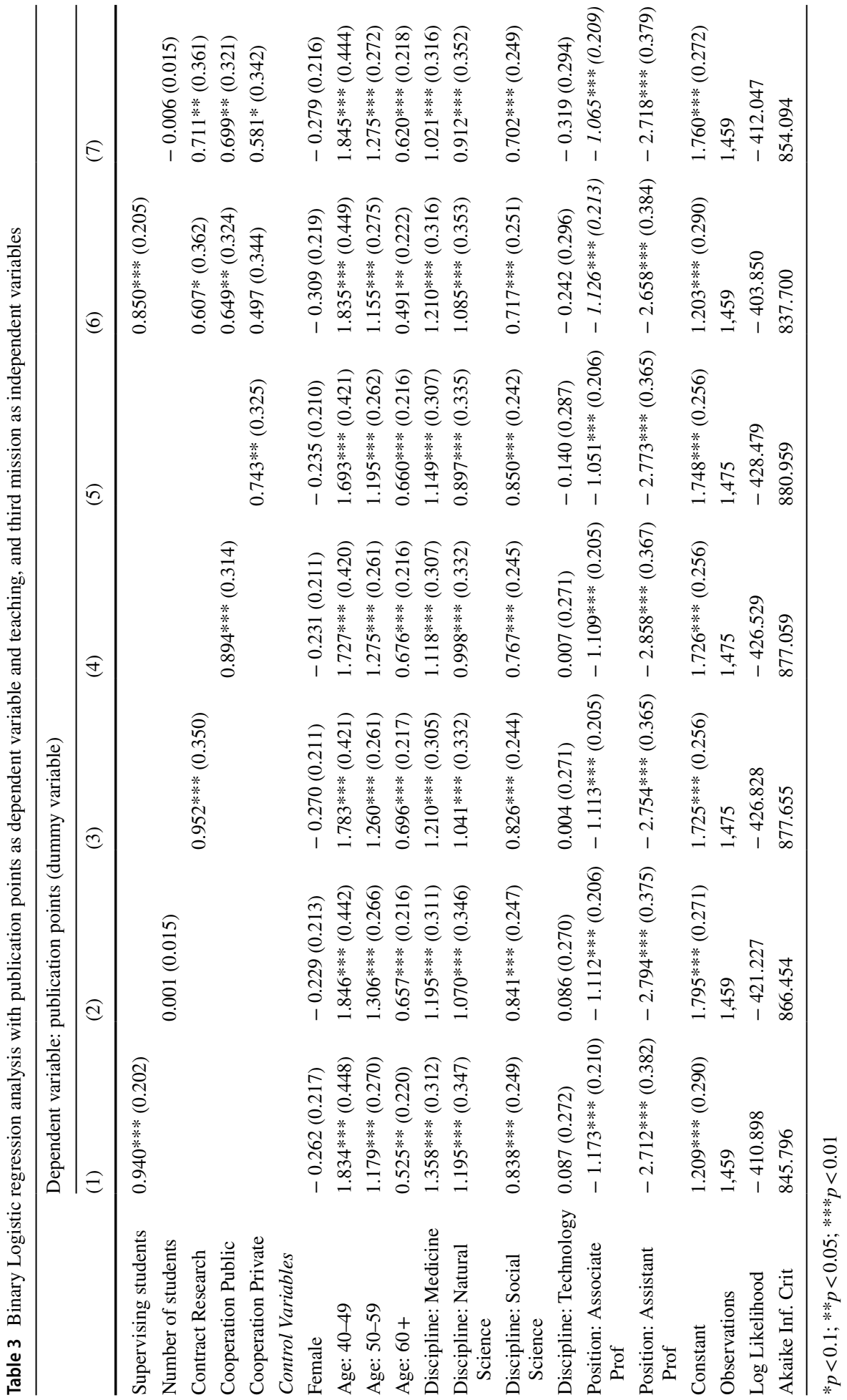


Supervising students

Not supervising students

Doing contract research

Not doing contract research

Cooperation with public sector

Not cooperating with public sector

Cooperation with public sector

Not cooperating with public sector
$11 \%$

$22 \%$
$6 \%$

$11 \%$

$11 \%$

$11 \%$

Fig. 2 The probabilities of having no publication points for male professors in technology

prior research (Smeby \& Gulbrandsen, 2005; Muscio et al., 2017; Banal-Estanol et al., 2015) we found a positive relationship between participating in external collaborations and research activity, but we did not find the same relationship when investigating research productivity.

These results on task complementarity illustrate the complexity involved. Third mission activities in the form of collaboration with private and public organisations can be closely related to research work that leads to scientific publications, as we find in this study. Commercialisation of research is also related to research activities, but after initial idea generation, the time spent on commercialisation is probably less connected to ongoing research and publication activities. Moreover, other studies of academics that are productive academic entrepreneurs (i.e. has many patents, license agreements etc.) often show that these are few and rather unique individuals. They tend to be senior, male academics in natural sciences and medicine, with unusually high scientific productivity (Perkmann et al., 2013). As an extra control measure, we carried out another analysis on STEM-researchers only. These analyses gave the same results as for our analyses on the whole population and hence confirmed our findings. Thus, even though some of these activities are more common in the STEM-fields, the overall results seem to be applicable across all fields. This does not mean that for some individuals there is a positive relationship between commercialisation and research performance, which is probably related to individual talent and specificity of the research activities that we do not capture in this study.

The third relationship we looked at was between third mission activities and educational tasks. Based on prior studies (Landry et al., 2010; Bianchini et al., 2016; Sanchez-Barriollungo, 2014; Wang et al., 2016) we expected that having a high volume of educational tasks would be negative for commercialisation, and that a moderate level of such tasks would be positive for research collaboration. Our results indicate that there is a significant, positive relationship between external collaboration and supervision of students. We do not find clear evidence that commercialisation is negatively related to supervision, as 
expected in proposition 4, as the evidence is too limited. In accordance with proposition 5 , we find that educational activities in the form of supervision has a positive relationship to participation in external collaborations, and we detect a small increased effect of numbers of students supervised. This result is in line with prior studies (Bozeman \& Boardman, 2013). Our results indicate that research collaboration with public sector organisations may be better aligned with support to students than industry collaboration. We do not have data to offer a detailed analysis of this, but we assume that public sector research collaboration is often organised as longer-term research projects, and hence may offer more opportunities to include students but also to pursue research. Moreover, as the sample included in the analysis covers a range of disciplines, including the social sciences and health sciences, public sector collaboration is more common among the informants than industry collaboration.

We interpret these results as in accordance with the expectation set forth about the positive relationship between supervision and to research collaboration, but we do not find support for the expected negative relationship between education and commercialisation, as expected by proposition 4 . These results are contrary to the results obtained by other researchers that have looked at the relationship in the opposite direction; i.e. they have looked at the impact of third mission activities on teaching or attitudes to teaching (Landry et al., 2010; Bianchini et al., 2016). It is however interesting to note that third mission activities do not deter teaching efforts, as it is sometimes portrayed, but that there might be positive spill-over effects here as well. The significance of our results is therefore difficult to determine. In line with Perkmann et al., (2013) we conclude that there is necessary to perform further research on the connection between third mission and educational activities.

It is also interesting to note that neither supervision nor external collaboration is associated with research productivity, but only with being an active researcher, as resources from such activities could be expected to support research activities in different ways. Moreover, it is also interesting to note that the combined effect of being involved in third-mission activities and supervising does not seem to impact research activity in a negative way, as we assumed in proposition 6 . We do find a negative relationship, but it is not significant. The latter finding is surprising, and needs to be investigated further.

We do see that for the larger part of our sample, combining different tasks is common and that it is feasible to combine tasks and still perform research to some extent. Individuals that do not publish also seem to have limited supervision and third mission tasks. This group may be in a career stage or have a position that entails limited attention to such tasks, for instance by being in a leadership position. The lack of attention to leadership and administrative duties is a shortcoming in the study, as these tasks also influence task composition and academic performance.

Overall, it does not seem that having multiple tasks rewards or punishes research productivity also when controlled for my scientific fields and positions, entailing that individual characteristics and motivations probably play an important role in determining research productivity. The survey data does not offer an opportunity to gain insights into how academics organise work and there is probably a lot of interesting individual variance that we have not been able to account for. Further research should address this shortcoming and look at academic multi-taskers to address the drawbacks and benefits of handling multiple work tasks. 
As seen in the literature section, a problem in research on this issue is the lack of standardised variables and a clear theoretical understanding of the relationships between the variables (Verburg et al., 2007). Research activities and performance are commonly captured by publication data (although they also are proxies for research activities), but educational and third mission activities on the other hand are broad categories that also vary significantly between fields of science. For such 'softer' or activity-based measures, we had to rely on information provided by the individuals themselves. In this paper, we opted for using numbers of students supervised as a proxy for educational activities as this approach has also been applied by other studies (Lin \& Bozeman, 2006; Kyvik \& Smeby, 1994). We acknowledge that this measure presents a limited part of the educational tasks performed by staff. Since we were interested in complementarity and trade-off with respect to work tasks, we were mainly interested in variables that measured the amount of time and effort spent on different tasks, hence quantitative indicators were preferred. We opted for using number of students supervised (graduate and undergraduate) as it would be easier for respondents to recall and this would hopefully give us a more objective assessment that subjective estimations of time spent on teaching.

Further research needs to address these shortcomings with a broader and more inclusive measurement of different educational activities in particular. Ideally, data from administrative records could support such an analysis, but these data are not available at the population level, but could be used in analysis on specific universities or departments. Our choice of variables might mean that the high degree of complementarity observed between supervision, research productivity and external research collaboration, might be an overestimation of this relationship in a positive sense. If we had used a broader variable to capture educational activities than supervision, a higher degree of trade-off and a clearer impact of threshold effects might have been observed. Further research should look into this issue.

Finally, data was collected in one specific context that may be rather different than what most university professors experience. In Norway, academic work is closely regulated, and work conditions are perhaps less competitive and more uniform that in other universities and higher education systems, such as in the US or UK. Also, the sample is only tenured staff, and tensions and stress in academic work may be very different for other groups of academic staff. The external validity of the findings in other contexts is perhaps limited, but the choice of settings was based on the premise that comparing individuals with similar work situations was important for the control of external factors. Further research should therefore look at a broader set of contexts and also include academics in different career tracks.

\section{Conclusion}

Bearing in mind the limitations, the results of this study suggest that there are some academic tasks that apparently go well together, whereas others do not. There seem to be complementarity between supervision and third mission activities, and a positive relationship between supervision, external research collaboration and research activities. Nonetheless, 
we see that having multiple responsibilities outside the realm of research (supervision, collaboration) does not punish nor does it offers significant rewards when it comes to research productivity. Thus, how academics balance a complex portfolio of activities and tasks, and how the different work tasks are connected might be rather idiosyncratic. Individual abilities, talents, time available for work and family obligations are other variables influencing academic work and how tasks are handled by academics. To gain a thorough understanding of this, detailed individual level data on academic work is needed. Moreover, these issues may be highly context sensitive, as the organisation of academic work, careers and incentive systems are highly specific. As this study was carried out in one country with its specific higher education policy framework, comparative studies of academic work in multiple institutional settings is needed in further research.

In terms of policy implications, higher education policies and institutional arrangements have tended to focus on supporting research-teaching connections and research-commercialisation linkages. Our analysis indicates also that this is a good priority as available knowledge and our results indicate that at the levels of individual academics, achieving complementarity between these tasks seem to be the most difficult to achieve in practice. At the same time, we observe an interesting link between supervision and third mission tasks, and in particular external collaboration. The education-third mission link has to a limited extent been addressed in policy and practice, and this is an area where further policy development is needed.

Finally, recruitment and career development practices in universities ask university professors to have a wide set of skills, essentially asking professors to be proficient multitaskers or be something akin to "five-legged sheep". We have argued that the potential for achieving the synergies should be based on a real potential that such tasks are complementary in everyday academic work. This study indicates that there are indeed both task trade-offs and task complementarities at play, and apparently rather few academics who are able to multitask and perform highly across a wide range of tasks. In light of recent efforts to develop multi-criteria career evaluation frameworks for academics, these results also indicates that broadening of skill-sets and competences of academics also carry costs that should be taken into account. A career policy that emphasises recruitment of different kinds of employees to a more diverse set of academic roles may represent the most efficient way to fulfil the multiple missions of universities in the end. Moreover, creating career development and assessment practices that support development of task complementarity and learning across tasks should be positive. This would entail for instance supporting academics' efforts in using their research in teaching or connecting teaching and societal engagement. Perspectives from work psychology and labour economics have long pinpointed that multi-tasking is only beneficial when it increases inter-task learning, but it is an open question whether there are ample support for such spill-over to occur in such a way that it leads to synergies rather than trade-off in the academic context.

\section{Appendix}

See Tables 4,5, 6, 7, 8, 9, 10 and 11. 


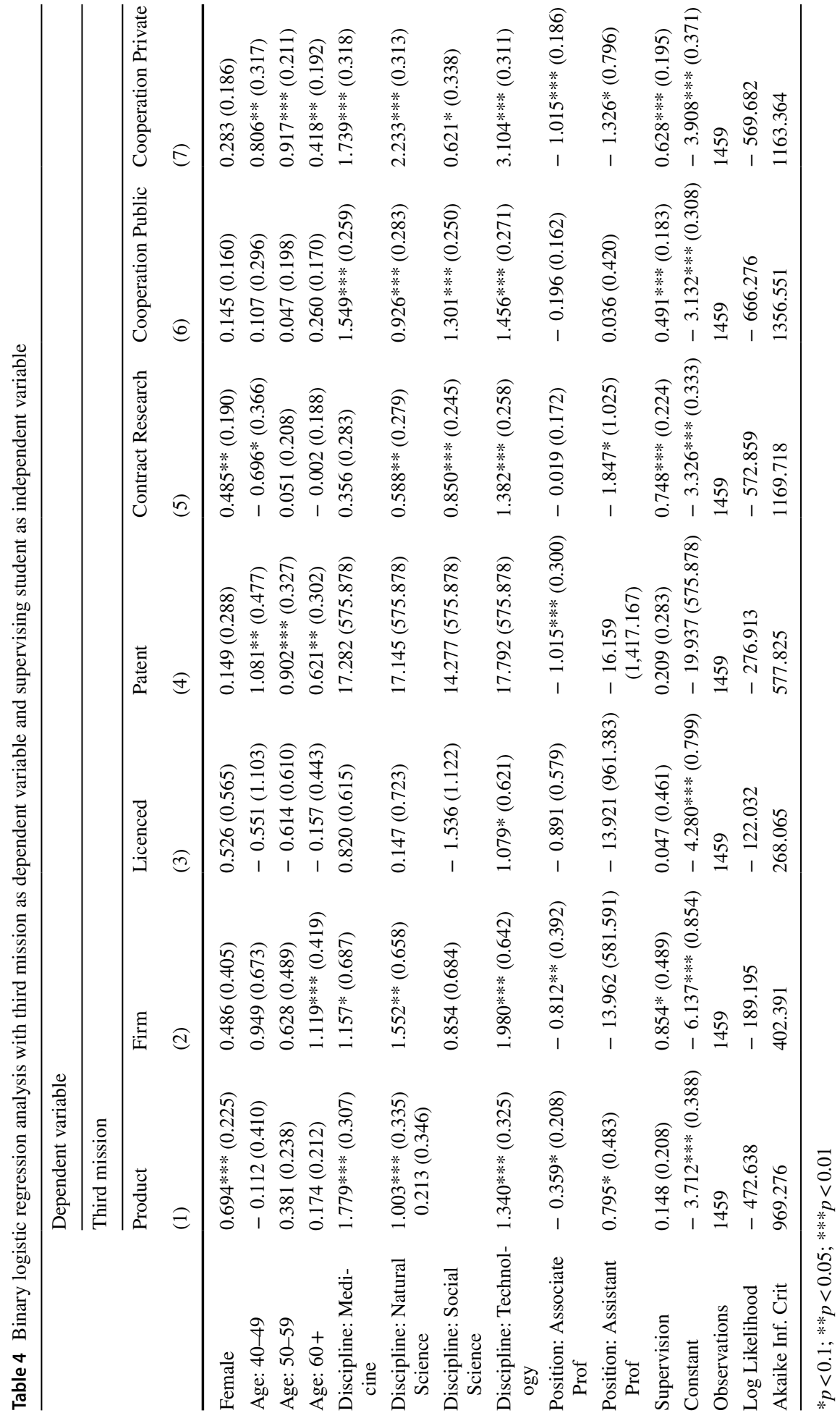




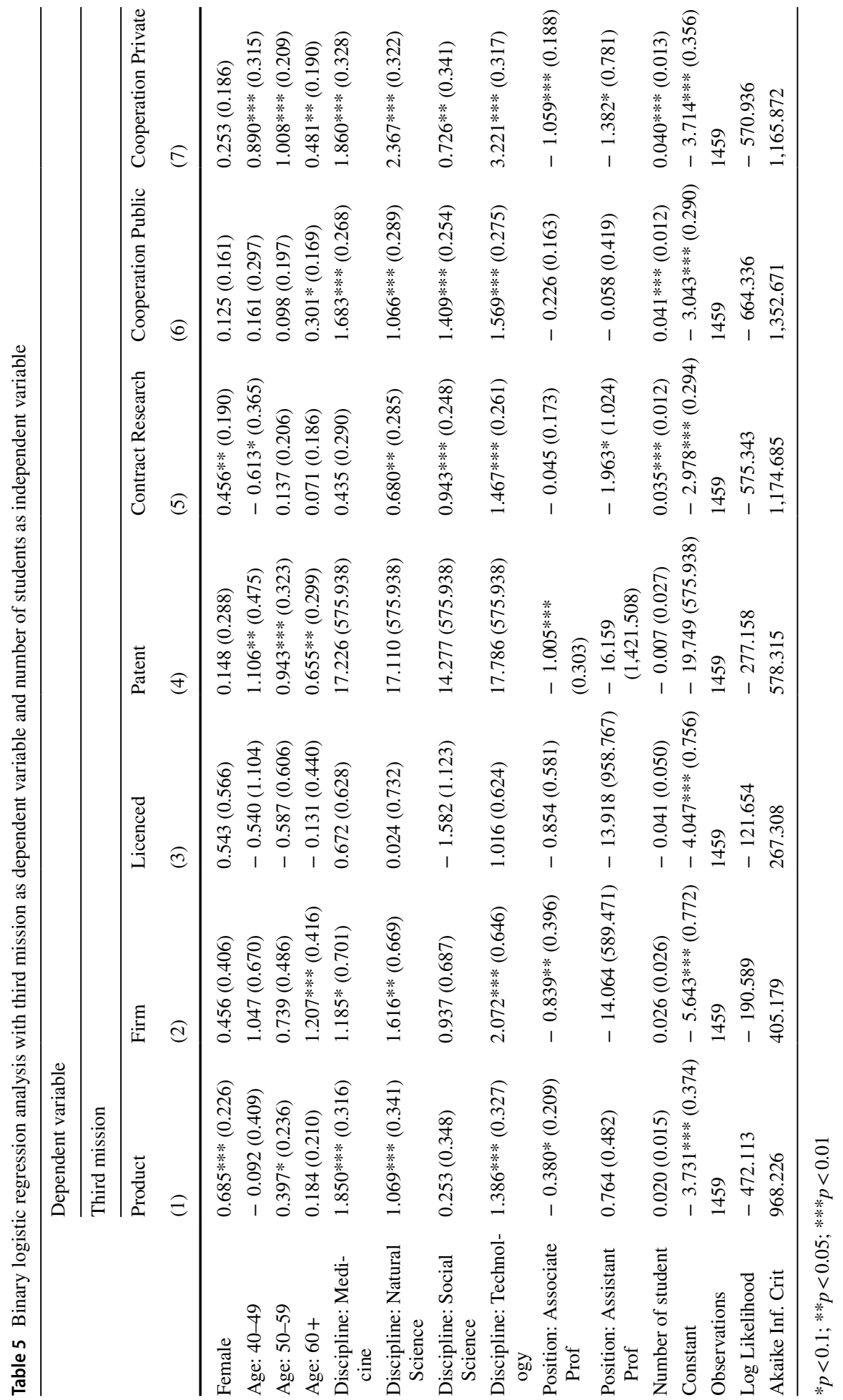




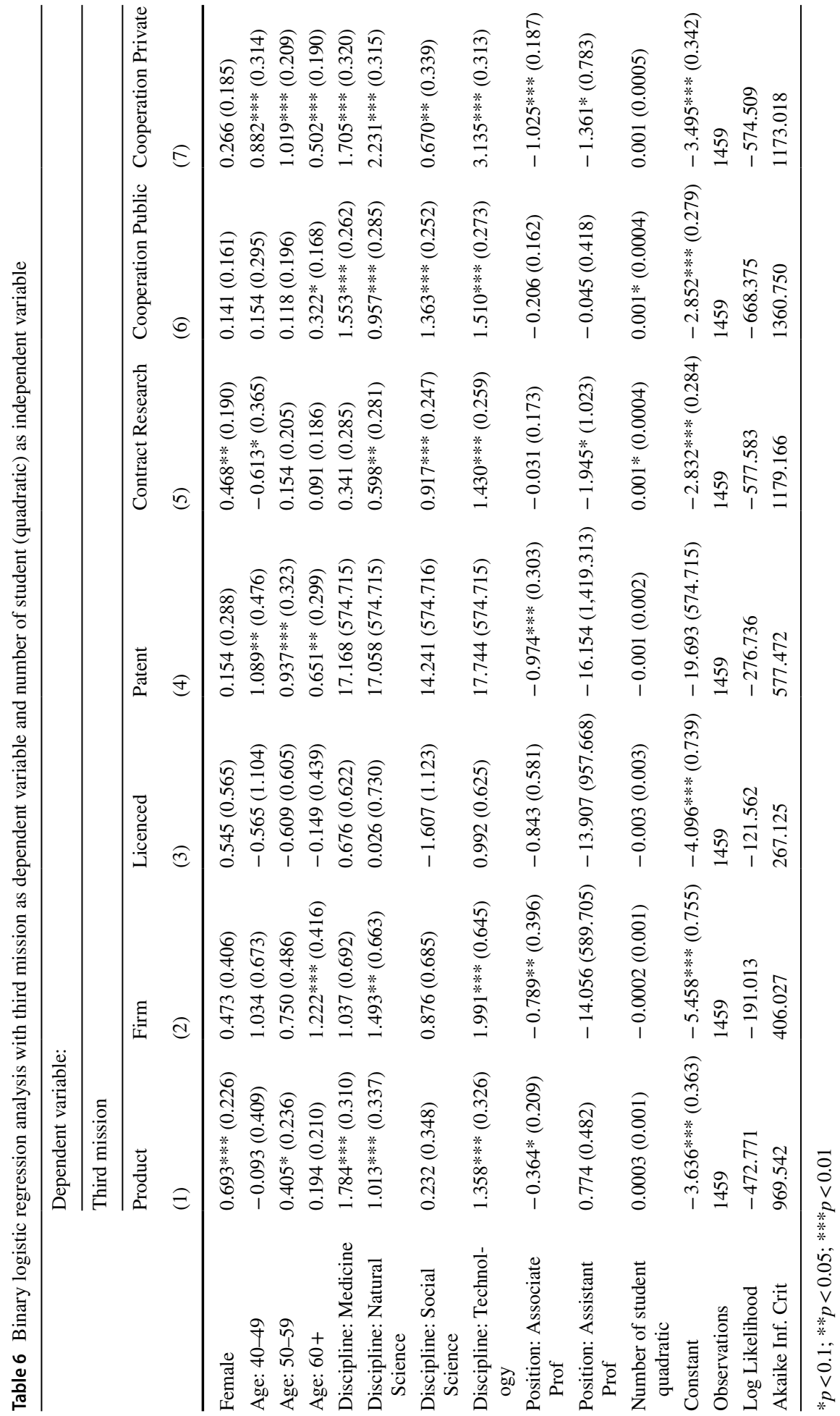




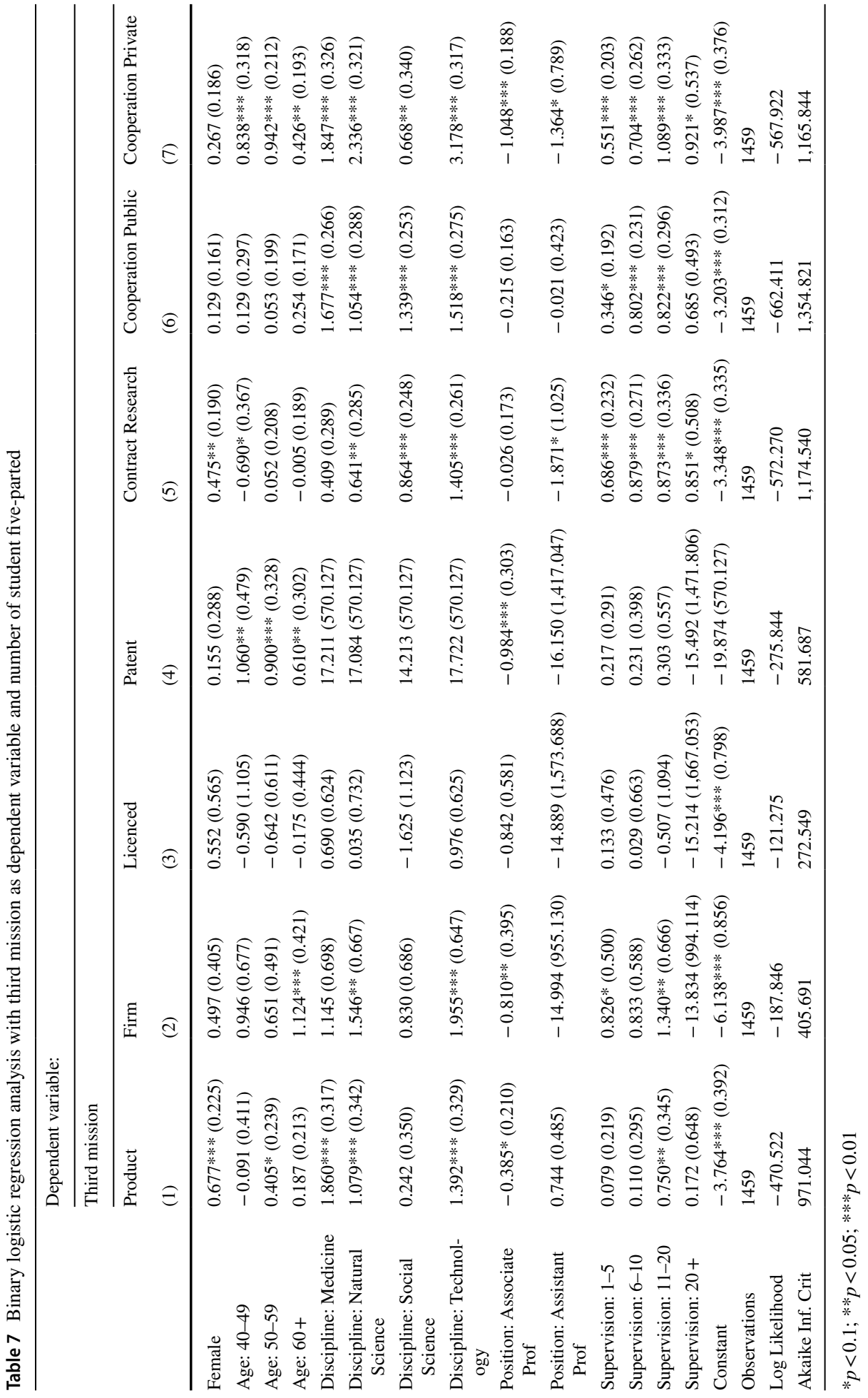




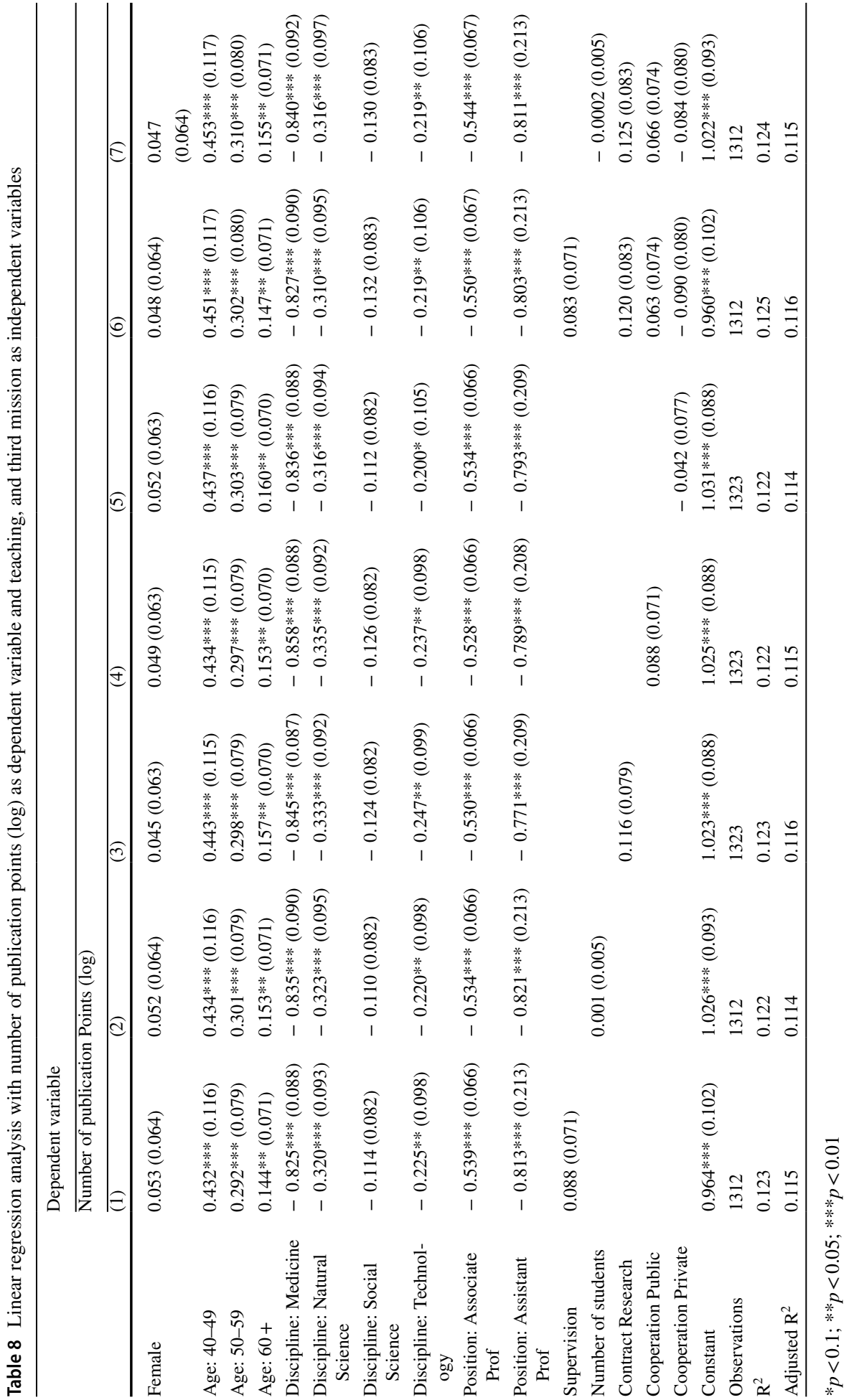


Table 9 Binary Logistic regression analysis with publication points as dependent variable and teaching as independent variables

Dependent variable

Publication points dummy

(1) (2) (3) (4)

\begin{tabular}{|c|c|c|c|c|}
\hline Female & $-0.262(0.217)$ & $-0.229(0.213)$ & $-0.224(0.213)$ & $-0.245(0.218)$ \\
\hline Age: $40-49$ & $1.834 * * *(0.448)$ & $1.846^{* * * *}(0.442)$ & $1.837 * * *(0.442)$ & $1.803 * * *(0.448)$ \\
\hline Age: $50-59$ & $1.179 * * *(0.270)$ & $1.306^{* * * *}(0.266)$ & $1.313 * * *(0.266)$ & $1.208 * * *(0.272)$ \\
\hline Age: $60+$ & $0.525 * *(0.220)$ & $0.657 * * *(0.216)$ & $0.660 * * *(0.216)$ & $0.544 * *(0.222)$ \\
\hline Discipline: Medicine & $1.358 * * *(0.312)$ & $1.195 * * *(0.311)$ & $1.170 * * *(0.309)$ & $1.261 * * *(0.317)$ \\
\hline $\begin{array}{l}\text { Discipline: Natural } \\
\text { Science }\end{array}$ & $1.195^{* * * *}(0.347)$ & $1.070 * * *(0.346)$ & $1.049 * * *(0.344)$ & $1.082 * * *(0.352)$ \\
\hline $\begin{array}{l}\text { Discipline: Social } \\
\text { Science }\end{array}$ & $0.838 * * *(0.249)$ & $0.841 * * *(0.247)$ & $0.824 * * *(0.247)$ & $0.792 * * *(0.252)$ \\
\hline $\begin{array}{l}\text { Discipline: Technol- } \\
\text { ogy }\end{array}$ & $0.087(0.272)$ & $0.086(0.270)$ & $0.075(0.270)$ & $0.035(0.274)$ \\
\hline $\begin{array}{l}\text { Position: Associate } \\
\text { Prof }\end{array}$ & $-1.173 * * *(0.210)$ & $-1.112 * * *(0.206)$ & $-1.104 * * *(0.206)$ & $-1.176^{* * *}(0.212)$ \\
\hline $\begin{array}{l}\text { Position: Assistant } \\
\text { Prof }\end{array}$ & $-2.712 * * *(0.382)$ & $-2.794 * * *(0.375)$ & $-2.790 * * *(0.374)$ & $-2.689 * * *(0.384)$ \\
\hline Supervision & $0.940 * * *(0.202)$ & & & \\
\hline Number of Students & & $0.001(0.015)$ & $-0.0003(0.0005)$ & \\
\hline Supervision: $1-5$ & & & & $1.187 * * *(0.232)$ \\
\hline Supervision: 6-10 & & & & $0.618 * *(0.272)$ \\
\hline Supervision: 11-20 & & & & $0.814 * *(0.356)$ \\
\hline Supervision: $20+$ & & & & $0.202(0.457)$ \\
\hline Constant & $1.209 * * *(0.290)$ & $1.795 * * *(0.271)$ & $1.822 * * *(0.263)$ & $1.242 * * *(0.291)$ \\
\hline Observations & 1459 & 1459 & 1459 & 1459 \\
\hline Log Likelihood & -410.898 & -421.227 & -421.070 & -407.236 \\
\hline Akaike Inf. Crit & 845.796 & 866.454 & 866.140 & 844.472 \\
\hline
\end{tabular}

$* p<0.1 ; * * p<0.05 ; * * * p<0.01$

In model 3 number of students is quadratic 


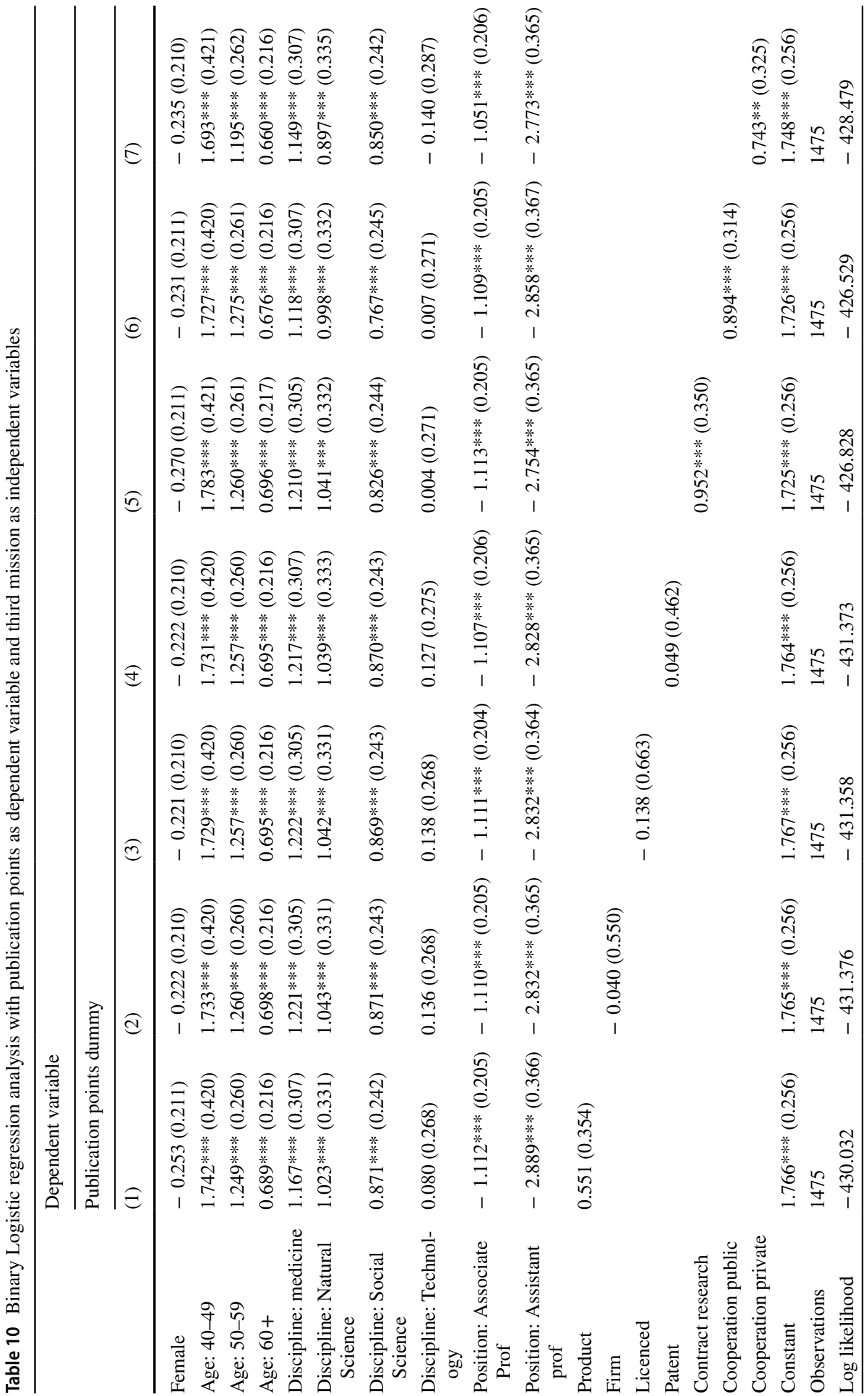




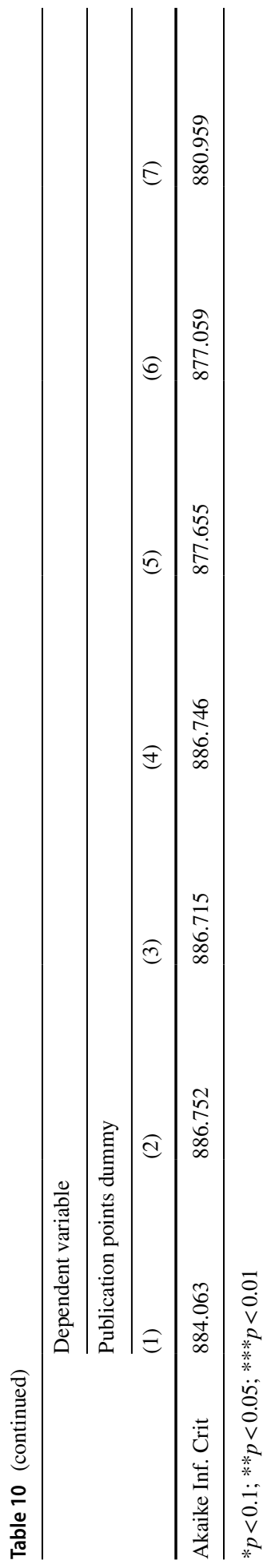

Din Springer 


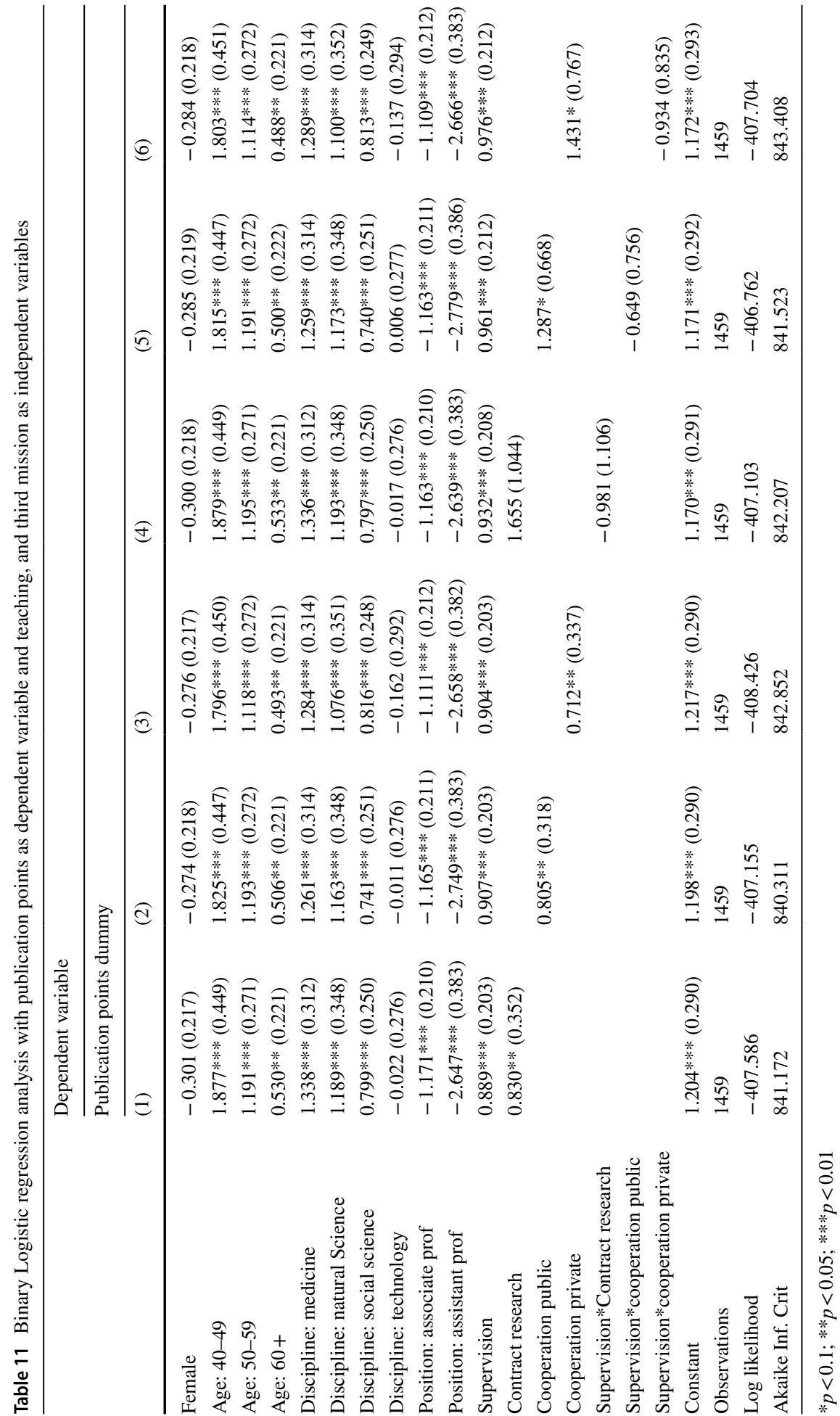


Acknowledgements The Survey used in the paper was developed by a research group lead by Nicoline Frølich at the Nordic Institute for Studies of Research, Education and Innovation called "Quality and cooperation-The Higher Education Sector and the Society". The authors have been part of this project, which was funded by the Norwegian Ministry of Education and Research. The authors acknowledge the support and insightful comments received from Nicoline Frølich, Siri Borlaug, Bjørn Stensaker, Mabel SanchezBarrioluengo, Siv-Elisabeth Skjelbred \& Claus Høijmark Jensen. Any mistakes or omissions remain the sole responsibility of the authors.

Funding Open access funding provided by University of Oslo (incl Oslo University Hospital).

Open Access This article is licensed under a Creative Commons Attribution 4.0 International License, which permits use, sharing, adaptation, distribution and reproduction in any medium or format, as long as you give appropriate credit to the original author(s) and the source, provide a link to the Creative Commons licence, and indicate if changes were made. The images or other third party material in this article are included in the article's Creative Commons licence, unless indicated otherwise in a credit line to the material. If material is not included in the article's Creative Commons licence and your intended use is not permitted by statutory regulation or exceeds the permitted use, you will need to obtain permission directly from the copyright holder. To view a copy of this licence, visit http://creativecommons.org/licenses/by/4.0/.

\section{References}

Abramo, G., D’Angelo, C. A., \& Di Costa, F. (2009). Research collaboration and productivity: Is there correlation? High Education, 57, 155.

Abreu, M., \& Grinevich, V. (2013). The nature of academic entrepreneurship in the UK: Widening the focus on entrepreneurial activities. Research Policy, 42(2), 408-422.

Artés, J., et al. (2017). Research performance and teaching quality in the Spanish higher education system: Evidence from a medium-sized university. Research Policy, 16, 19-29.

Banal-Estañol, A., Jofre-Bonet, M., \& Lawson, C. (2015). The double-edged sword of industry collaboration: Evidence from engineering academics in the UK. Research Policy, 44(6), 1160-1175.

Bentley, P. J., \& Kyvik, S. (2012). Academic work from a comparative perspective: A survey of faculty working time across 13 countries. Higher Education, 63(4), 529-547.

Bianchini, S., Lissoni, F., Pezzoni, M., \& Zirulia, L. (2016). The economics of research, consulting, and teaching quality: Theory and evidence from a technical university. Economics of Innovation and New Technology, 25(7), 668-691.

Bozeman, B., \& Boardman, C. (2013). Academic faculty in university research centers: Neither capitalism's slaves nor teaching fugitives. The Journal of Higher Education, 84(1), 88-120.

Bozeman, B., Fay, D., \& Slade, C. P. (2013). Research collaboration in universities and academic entrepreneurship: The-state-of-the-art. The Journal of Technology Transfer, 38(1), 1-67.

Braxton, J. M. (1996). Contrasting perspectives on the relationship between teaching and research. New Directions for Institutional Research, 1996(90), 5-14.

Breschi, S., Lissoni, F., \& Montobbio, F. (2007). The scientific productivity of academic inventors: New evidence from Italian data. Econom. Innovation New Tech., 16(2), 101-118.

Buenstorf, G. (2009). Is commercialization good or bad for science? Individual-level evidence from the Max Planck Society. Research Policy, 38(2), 281-292.

Christiansen, F. V. (2016). Stillingsstrutkurens betydning for samspilet mellem forskning og undervisning. Dansk Universitetspaedagogisk Tidskrift, 11, 31.

Czarnitzki, D., Grimpe, C., \& Toole, A. A. (2015). Delay and secrecy: Does industry sponsorship jeopardize disclosure of academic research? Industrial and Corporate Change, 24(1), 251-279.

Duff, A., \& Marriott, N. (2017). The teaching-research gestalt: The development of a discipline-based scale. Studies in Higher Education, 42(12), 2406-2420.

Etzkowitz, H. (1998). The norms of entrepreneurial science: Cognitive effects of the new university-industry linkages. Research Policy, 27(8), 823-833.

Eurostat (2019). Harmonised European Time Use Surveys. 2018 Guidelines. Eurostat.

Fini, R., Perkmann, M., \& Ross, J. M. (2021). Attention to exploration: The effect of academic entrepreneurship on the production of scientific knowledge. Organization Science. https://doi.org/10.1287/orsc. 2021.1455 
Fox, M. F. (1992). Research, teaching, and publication productivity: mutuality versus competition in academia. Sociology of Education, 65(4), 293-305.

Frølich, N., Wendt, K., Reymert, I., Tellmann, S. M., Elken, M., Kyvik, S., Vabø, A., \& Larsen, E. H. (2018). Academic career structures in Europe: Perspectives from Norway, Denmark, Sweden, Finland, the Netherlands, Austria and UK. NIFU Report. Nordic Institute for Studies in Innovation, Research and Education.

Fudickar, R., Hottenrott, H., \& Lawson, C. (2018). What's the price of academic consulting? Effects of public and private sector consulting on academic research. Industrial and Corporate Change, 27(4), 699-722.

García-Gallego, A., et al. (2015). (How) Do reseacher and administrative duties affect university professors' teaching? Applied Economics, 47(45), 4868-4883.

Geuna, A., \& Nesta, L. J. (2006). University patenting and its effects on academic research: The emerging European evidence. Research Policy, 35(6), 790-807.

Gulbrandsen, M., \& Smeby, J. C. (2005). Industry funding and university professors' research performance. Research Policy, 34(6), 932-950.

Hattie, J., \& Marsh, H. W. (1996). The relationship between research and teaching: A meta-analysis. American Journal Research Association, 66(4), 507-542.

Hayter, C. S., Rasmussen, E., \& Rooksby, J. H. (2020). Beyond formal university technology transfer: Innovative pathways for knowledge exchange. The Journal of Technology Transfer, 45(1), 1-8.

Kossi, Y., Lesueur, J. Y., \& Sabatier, M. (2016). Publish or teach? The role of the scientific environment on academics' multitasking. Industrial and Corporate Change, 25(3), 487-506.

Kyvik, S. (2004). Structural changes in higher education systems in western Europe. Higher Education in Europe, 29, 393-409.

Kyvik, S. (2013). The academic researcher role: Enhancing expectations and improved performance. Higher Education, 65(4), 525-538.

Kyvik, S., \& Smedby, J.-C. (1994). Teaching and research. The relationship between the supervision of graduate students and faculty research performance. Higher Education, 28(2), 227-239.

Landry, R., Saihi, M., Amara, N., \& Ouimet, M. (2010). Evidence on how academics manage their portfolio of knowledge transfer activities. Research Policy, 39(10), 1387-1403.

Laredo, P. (2007). Revisiting the third mission of universities: Toward a renewed categorization of university activities? Higher Education Policy, 20(4), 441-456.

Larsen, M. T. (2011). The implications of academic enterprise for public science: An overview of the empirical evidence. Research Policy, 40(1), 6-19.

Lee, J. J., \& Rhoads, R. A. (2004). Faculty entrepreneurialism and the challenge to undergraduate education at research universities. Research in Higher Education, 45(7), 739-760.

Lee, S., \& Bozeman, B. (2005). The impact of research collaboration on scientific productivity. Social Studies of Science, 35(5), 673-702.

Lin, F. (2008). Solving multicollinearity in the process of fitting regression model using the nested estimate procedure. Quality and Quantity, 42, 417-426.

Lin, M.-W., \& Bozeman, B. (2006). Researchers' industry experience and productivity in university-industry research centers: A scitentific and teachnical human capital explanation. Journal of Technology Transfer, 31, 269-290.

Lindbeck, A., \& Snower, D. J. (2000). Multitask learning and the reorganization of work: From tayloristic to holistic organization. Journal of Labor Economics, 18(3), 353-376.

Mitchell, J. E., \& Rebne, D. S. (1995). Nonlinear effects of teaching and consulting on academic research productivity. Socio-Economic Planning Sciences, 29(1), 47-57.

Molas-Gallart, J., Salter, A., Patel, P., Scott, A., \& Duran, X. (2002). Measuring third stream activities. Final report to the Russell Group of Universities. University of Sussex.

Muscio, A., Ramaciotti, L., \& Rizzo, U. (2017). The complex relationship between academic engagement and research output: Evidence from Italy. Science and Public Policy, 44(2), 235-245.

Nybom, T. (2003). The Humboldt legacy: Reflections on the past, present, and future of the European university. Higher Education Policy, 16(2), 141-159.

Pelz, D. C., \& Andrews, F. M. (1966). Autonomy, coordination, and stimulation, in relation to scientific achievement. Behavioral Science, 11(2), 89-97.

Perkmann, M., et al. (2013). Academic engagement and commercialisation: A review of the literature on university-industry relations. Research Policy, 42(2), 423-442.

Roche, M. P., Conti, A., \& Rothaermel, F. T. (2020). Different founders, different venture outcomes: A comparative analysis of academic and non-academic startups. Research Policy, 49(10), 104062.

Rothaermel, F. T., Agung, S. D., \& Jiang, L. (2007). University entrepreneurship: A taxonomy of the literature. Industrial and Corporate Change, 16(4), 691-791. 
Sánchez-Barrioluengo, M. (2014). Articulating the 'three-missions' in Spanish universities. Research Policy, 43(10), 1760-1773.

Sivertsen, G. (2016). Publication-based funding: The Norwegian model. In M. Ochsner, S. E. Hug, \& H.-D. Daniel (Eds.), Research assessment in the humanities. Springer.

Stolze, A., \& Sailer, K. (2021). Advancing HEIs' third-mission through dynamic capabilities: The role of leadership and agreement on vision and goals. Journal of Technology Trans, 2021, 1-25.

Van den Brink, M., \& Benschop, Y. (2011). Gender practices in the construction of academic excellence: Sheep with five legs. Organization, 19/4, 507-524.

Van Looy, B., Ranga, M., Callaert, J., Debackere, K., \& Zimmermann, E. (2004). Combining entrepreneurial and scientific performance in academia: Towards a compounded and reciprocal Matthew-effect? Research Policy, 33(3), 425-441.

Verburgh, A., Elen, J., \& Lindblom-Ylänne, S. (2007). Investigating the myth of the relationship between teaching and research in higher education: A review of empirical research. Studies in Philosophy and Education, 26(5), 449-465.

Wang, Y., Hu, R., Li, W., \& Pan, X. (2016). Does teaching benefit from university-industry collaboration? Investigating the role of academic commercialization and engagement. Scientometrics, 106(3), $1037-1055$.

Wiers-Jenssen, J. (2015). Studentenes vurderinger av utdanning og lærested. Kvalitet, Kapasitet og Relevans'. In N. Frølich (Ed.), Hva skjer i universiteter og høgskoler (pp. 312-332). Cappelen Damm Akademisk.

Publisher's Note Springer Nature remains neutral with regard to jurisdictional claims in published maps and institutional affiliations. 